\title{
Printable Zinc-Ion Hybrid Micro-Capacitors for Flexible Self-Powered Integrated Units
}

Cite as

Nano-Micro Lett.

(2021) 13:19

Received: 26 February 2020

Juan Zeng ${ }^{1}$, Liubing Dong ${ }^{2}$, Lulu Sun ${ }^{3}$, Wen $_{W^{\prime}}{ }^{3}$, Yinhua Zhou ${ }^{3}$, Lu Wei $^{1}{ }^{凶}$, Xin Guo ${ }^{1 凶}$

Accepted: 30 September 2020

Published online: 5 November 2020

(C) The Author(s) 2020

\section{HIGHLIGHTS}

- This work is a new guide for the design of on-chip energy integrated systems toward the goal of developing highly safe, economic, and long-life smart wearable electronics.

- The biomass kelp-carbon based on unique 3D micro-/nanostructure combined with multivalent ion storage contributes to high capacity of the $\mathrm{Zn}$-ion hybrid capacitor.

- The flexible solar-charging self-powered system with printed $\mathrm{Zn}$-ion hybrid micro-capacitor as energy storage module exhibits fast photoelectric conversion/storage rate, good mechanical robustness, and cyclic stability.

\begin{abstract}
Wearable self-powered systems integrated with energy conversion and storage devices such as solar-charging power units arouse widespread concerns in scientific and industrial realms. However, their applications are hampered by the restrictions of unbefitting size matching between integrated modules, limited tolerance to the variation of input current, reliability, and safety issues. Herein, flexible solar-charging self-powered units based on printed $\mathrm{Zn}$-ion hybrid micro-capacitor as the energy storage module is developed.
\end{abstract}

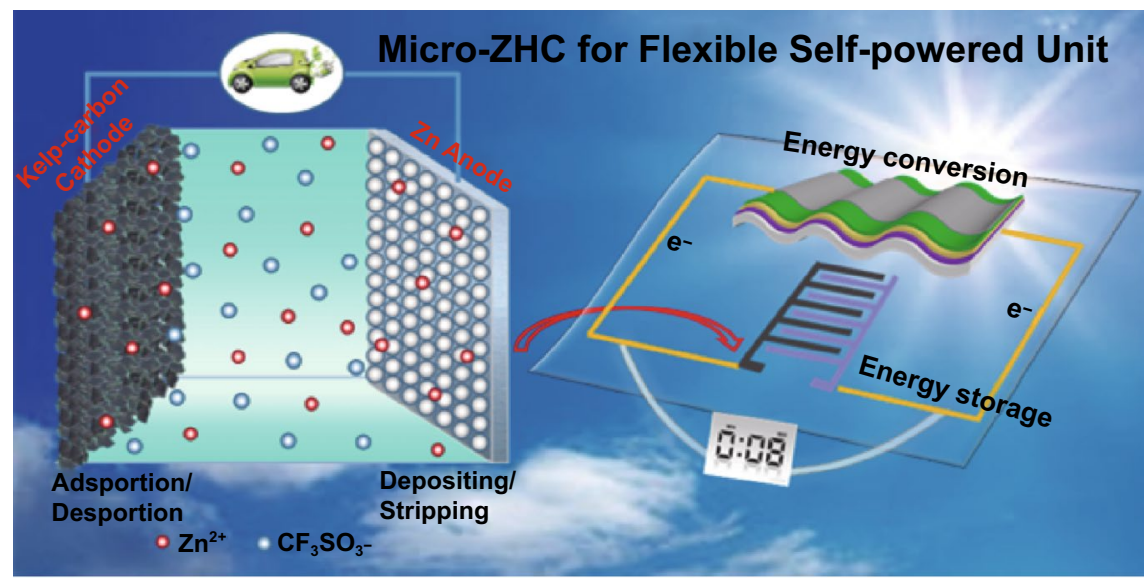
Unique 3D micro-/nano-architecture of the biomass kelp-carbon combined with multivalent ion $\left(\mathrm{Zn}^{2+}\right)$ storage endows the aqueous $\mathrm{Zn}$-ion hybrid capacitor with high specific capacity (196.7 $\mathrm{mAh} \mathrm{g}^{-1}$ at $0.1 \mathrm{~A} \mathrm{~g}^{-1}$ ). By employing an in-plane asymmetric printing technique, the fabricated quasi-solid-state Zn-ion hybrid microcapacitors exhibit high rate, long life and energy density up to $8.2 \mu \mathrm{Wh} \mathrm{cm}^{-2}$. After integrating the micro-capacitor with organic solar cells, the derived self-powered system presents outstanding energy conversion/storage efficiency $\left(\eta_{\text {overall }}=17.8 \%\right)$, solar-charging cyclic stability $(95 \%$ after 100 cycles), wide current tolerance, and good mechanical flexibility. Such portable, wearable, and green integrated units offer new insights into design of advanced self-powered systems toward the goal of developing highly safe, economic, stable, and long-life smart wearable electronics.

KEYWORDS Zinc-ion hybrid capacitor; Kelp-carbon; Zinc metal anode; Multivalent ion storage; Self-powered unit

LuWei, lwei@hust.edu.cn; Xin Guo,xguo@hust.edu.cn

1 State Key Laboratory of Material Processing and Die \& Mould Technology, School of Materials Science and Engineering, Huazhong University of Science and Technology, Wuhan 430074, People's Republic of China

2 College of Chemistry and Materials Science, Jinan University, Guangzhou 511443, People's Republic of China

3 Wuhan National Laboratory for Optoelectronics, School of Optical and Electronic Information, Huazhong University of Science and Technology, Wuhan 430074, People's Republic of China 


\section{Introduction}

Wearable electronics need to be miniature, portable, highly integrated, and conformable to human skin or other tissues $[1,2]$. Various human-machine interfaces, mobile power supplies, and display devices are expected to be integrated as multifunctional wearable systems, which would significantly improve the quality of our lives [3-5]. To build an independent functional wearable system, an energy conversion/harvesting-storing module serving as a power supply is prerequisite to other functional system components $[6,7]$.

In terms of energy conversion module, photovoltaic devices that convert solar energy to electric energy are omnipresent for harnessing clean and massive solar energy [8]. Yet solar energy is intermittent, unpredictable, and available only during the daytime. The unstable output energy is incapable of powering functional system persistently. Consequently, energy requires to be stored in a trustworthy module for subsequent use. Among numerous burgeoning energy storage devices, supercapacitors with high power density, fast charge-discharge rate, particularly the satisfying tolerance to variation of input current, have attracted great attention $[9,10]$. Following characteristics make them very suitable to store the converted solar energy by photovoltaic devices to build self-powered systems: (i) two devices (i.e., photovoltaic device and supercapacitor) complement each other. Photovoltaic devices continuously power the supercapacitors to resolve the shortcoming of low energy density for supercapacitors; the converted energy by photovoltaic devices is stored by the supercapacitor for use to resolve its shortcoming of intermittent source; (ii) it is a green energy system that does not need extra charging equipment, which has referential significance to other energy integration systems.

Supercapacitors suffer from relatively low energy density compared with various batteries, hindering their practical applications in advanced wearable electronics. Thus, to improve energy density is an eternal research objective for supercapacitors, and promising strategies care: (i) increasing the capacitance by introducing pseudocapacitive electrode materials; (ii) enhancing cell voltage by using novel electrolytes or constructing asymmetric devices [11-13]. Hybrid capacitors (a type of asymmetric supercapacitors) with one battery-type electrode as energy source and one capacitive electrode as power source are double-benefited
$[14,15]$. Various univalent metal ion hybrid capacitors, such as lithium-ion hybrid capacitors, sodium-ion hybrid capacitors, and potassium-ion hybrid capacitors, have been studied [16]. Nevertheless, alkali metals ( $\mathrm{Li}, \mathrm{Na}$, and $\mathrm{K}$ ) are extremely reactive, and introduced organic electrolytes are flammable, causing security risks. In recent years, multivalent ion storage mechanisms (e.g., $\mathrm{Zn}^{2+}, \mathrm{Mg}^{2+}, \mathrm{Ca}^{2+}$, and $\mathrm{Al}^{3+}$ ) have been put forward, which may provide fast charge transfer dynamics, high capacity, and energy density [17]. Among them, $\mathrm{Zn}$-ion hybrid capacitors (ZHCs) are considered as research hotspot by virtue of their unique merits including high safety, low-cost, high capacity, and long cycle life $[18,19]$. Safety is a main concern for wearable electronic devices. Exploiting ZHCs based on quasi-solid-state aqueous electrolyte can surmount the hazards of flammability and electrolyte leakage, while improve energy density.

To match wearable electronics, power sources with traits of miniature, planar, reliable, and easy to integrate are demanded [20]. Micro-ZHCs based on planar interdigital structure can meet the above requirements. However, the studies on asymmetric micro-devices are still in their nascent stage owing to the difficulty in building micro-asymmetric configuration and processing with different electrode materials. To the best of our knowledge, solar-charging self-powered system based on micro-ZHCs as the energy storage module has not been reported yet.

Herein, we fabricate aqueous ZHCs and quasi-solid-state micro-ZHCs, targeting flexible solar-charging self-powered system. The aqueous ZHCs are constructed with distinctive biomass kelp-carbon as cathode, $\mathrm{Zn}$ foil as anode and zinc trifluoromethane sulfonate $\left[\mathrm{Zn}\left(\mathrm{CF}_{3} \mathrm{SO}_{3}\right)_{2}\right]$ aqueous solution as electrolyte. The unique 3D micro-/nano- architecture of the kelp-carbon enables a high-rate and long-life ZHC; the asymmetric cell structure and multivalent ion $\left(\mathrm{Zn}^{2+}\right)$ storage result in a high specific capacity and energy density of the device. Further, flexible quasi-solid-state micro-ZHCs based on the screen printed kelp-carbon cathode, $\mathrm{Zn}$ powder anode and $\mathrm{Zn}\left(\mathrm{CF}_{3} \mathrm{SO}_{3}\right)_{2}$ /polyacrylamide (PAM) hydrogel electrolyte are fabricated on polyimide (PI) substrate. Screen printing technique is considered as a universal approach and applicable for scaled-up fabrication, which has the prospect of commercialization and gets rid of the cost dilemma faced by wearable self-powered devices in practical applications. The fabricated micro-ZHCs possess the virtues of integrated planar interdigital structure, excellent electrochemical 
performances, low cost, and high security. Moreover, direct printing such micro-ZHCs on chip with flexible organic solar cells (OSCs) enables the construction of solar-charging selfpowered units with simplified configurations and mechanical robustness. The derived integrated system exhibits fast photoelectric conversion/storage characteristics, wide current tolerance, continuous self-powering and wearable features, demonstrating potential for applications in healthcare, human-machine interfaces, and intelligent robotics.

\section{Experimental Section}

\subsection{Materials Preparation}

\subsubsection{Preparation of Kelp-Carbon}

The preparation method of kelp-carbon refers to our previous work [21]. Kelp blades (for food) were purchased from local farmers' market. Before using, they were washed with deionized water and dried at $70{ }^{\circ} \mathrm{C}$ overnight. For carbonization, the kelp-blades were heated to $600{ }^{\circ} \mathrm{C}$ for $2 \mathrm{~h}$ under $\mathrm{Ar}$ atmosphere in a tube furnace. For activation, the carbonaceous precursor was ground into powders and then impregnated in $\mathrm{KOH}$ solution with a mass ratio of 1:4 (carbon: $\mathrm{KOH})$. The mixed slurry was heat-treated at $120^{\circ} \mathrm{C}$ for $24 \mathrm{~h}$ in a vacuum oven and then was heated to $800{ }^{\circ} \mathrm{C}$ for $3 \mathrm{~h}$ under Ar flow in a tube furnace. Afterward, the activated samples were thoroughly washed with $10 \mathrm{wt} \% \mathrm{HCl}$ solution and deionized water, until neutral $\mathrm{pH}$ was achieved. After drying, kelp-carbon was obtained. Compared with our previous work [21], the main difference in the preparation process lies in the activation temperature for the kelp-carbon. Higher activation temperature benefits to widen the pore size of the activated carbon.

\subsubsection{Preparation of $\mathrm{Zn}\left(\mathrm{CF}_{3} \mathrm{SO}_{3}\right)_{2}$-PAM Hydrogel Electrolyte}

Acrylamide monomer powders (4.2 g) were dissolved in deionized water $(21 \mathrm{~mL})$ with stirring for $0.5 \mathrm{~h}$ to obtain a uniform solution. Then, N,N'-methylenebisacrylamide (0.01 wt \%), N,N,N',N'-tetramethylethylenediamine
(0.09 wt $\%)$, and ammonium persulfate $(0.1 \mathrm{wt} \%)$ were added into the solution and stirred uniformly. After degassing by ultrasonic treatment and vacuum, the obtained solution was poured into a glass mold and heated at $60{ }^{\circ} \mathrm{C}$ for $8 \mathrm{~h}$. Afterward, the as-prepared polymer gel was soaked in $2 \mathrm{M}$ $\mathrm{Zn}\left(\mathrm{CF}_{3} \mathrm{SO}_{3}\right)_{2}$ aqueous solution for more than $24 \mathrm{~h}$ to reach the ion balance point.

\subsection{Devices Preparation}

\subsubsection{Assembly of Aqueous ZHCs}

Aqueous ZHCs were assembled using a typical coin cell structure (CR2016), with kelp-carbon as cathode material and Zn foil (thickness of $70 \mu \mathrm{m}$ ) as anode. The cathode was prepared by coating electrode slurry (the mass ratio of kelp-carbon/ PVDF was 9:1) on stainless foil. The specific mass loading of the cathode material was $0.57-1.13 \mathrm{mg} \mathrm{cm}^{-2}$, the thickness of the cathode was $\sim 0.02 \mathrm{~mm}$, and the diameter of the electrode was $10 \mathrm{~mm}$. $2 \mathrm{M} \mathrm{Zn}\left(\mathrm{CF}_{3} \mathrm{SO}_{3}\right)_{2}$ aqueous solution was used as the electrolyte (with a $\mathrm{pH}$ value of $\sim 5.5$ ), and commercial polypropylene film (MPF30, NKK) was utilized as the separator. For control experiment, ZHCs based on commercial activated carbon as cathode [TF-B520//2 $\left.\mathrm{M} \mathrm{Zn}\left(\mathrm{CF}_{3} \mathrm{SO}_{3}\right)_{2} / / \mathrm{Zn}\right]$ were also assembled.

\subsubsection{Construction of Flexible Quasi-Solid-State Micro-ZHCs}

Firstly, interdigital Au layer (200 nm in thickness) acting as current collector was patterned on flexible PI substrate with designed mask by using magnetron sputtering (Amod, Angstrom Engineering Inc.). Next, kelp-carbon paste (80\% kelpcarbon and $20 \%$ organic vehicle composing of butyl carbitol, ethyl-cellulose, terpineol, din-butyl phthalates, and span85) was screen-printed (PHP-1515, Hotting Screen Printing Equipment Co. LTD) on the one side of the Au current collector fingers, and $\mathrm{Zn}$ paste ( $80 \% \mathrm{Zn}$ powder and $20 \%$ organic vehicle) was screen-printed on the other side of the Au current collector fingers to fabricate the asymmetric microelectrodes. The printed micro-device was annealed at $200{ }^{\circ} \mathrm{C}$ for $2 \mathrm{~h}$ to remove the organic vehicle. Finally, a piece of $\mathrm{Zn}\left(\mathrm{CF}_{3} \mathrm{SO}_{3}\right)_{2}-\mathrm{PAM}$ hydrogel electrolyte was coated on the interdigital electrodes 
with copper tape employed as the wire lead, and encapsulated with polyethylene film $(20 \mu \mathrm{m}$ in thickness $)$.

\subsubsection{Preparation of Flexible OSCs}

The detailed preparation process of flexible OSCs was provided in supporting information.

\subsubsection{Construction of Flexible Solar-Charging Integrated Units}

To deliver required working voltage, a micro-ZHC and four OSCs connected in series are integrated onto flexible polyethylene terephthalate (PET) substrate (110 $\mu \mathrm{m}$ in thickness) with copper foil tape as the interconnected wire. The active areas of the micro-ZHC and the four-junction OSCs are 0.0352 and $0.3 \mathrm{~cm}^{2}$, respectively. The entire device was sealed with polyethylene film.

\subsection{Materials and Characterizations}

Materials and characterizations on the morphology, structure, and porosity of kelp-carbon, electrochemical measurements, and calculations are provided in supporting information.

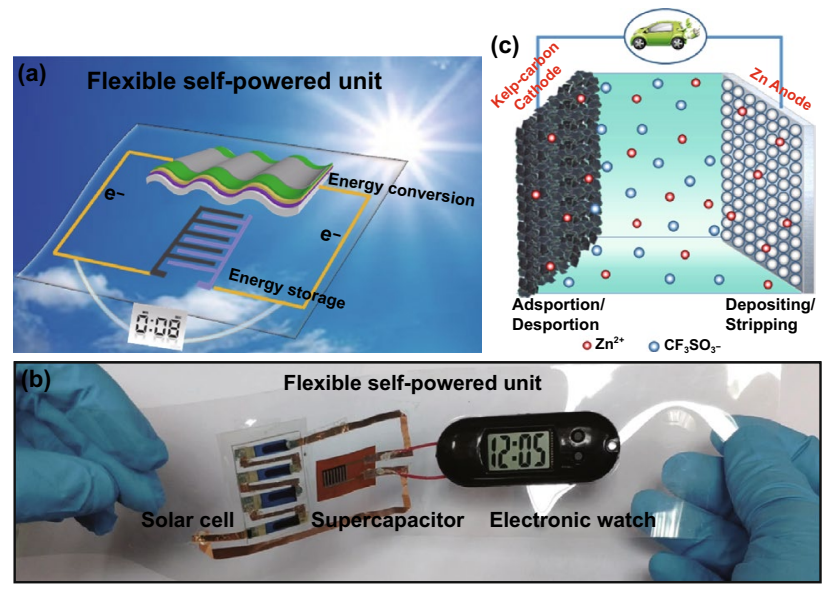

Fig. 1 a Graphical illustration of the solar-charging self-powered unit. b Proof-of-concept demonstration of the flexible solar-charging self-powered unit. $\mathbf{c}$ Working mechanism of the developed ZHC

\section{Results and Discussion}

\subsection{Configuration of the Solar-Charging Self-Powered Unit}

Figure 1a illustrates the configuration of the constructed flexible self-powered unit consisting of a piece of flexible PET substrate, energy conversion module (i.e., flexible OSCs) and an energy storage module (i.e., flexible micro$\mathrm{ZHC}$ ). Once the integrated unit is exposed to sunlight, the OSCs convert photo-irradiation into electricity and charge the micro-ZHC (solar-charging). The self-powered unit can power electronic devices during daylight, in doors and even at the time of discontinuous illumination or no light without external charging supply. As individual component is flexible and the entire integrated unit complies with an inplane design, it endows the system high flexibility. Figure $1 \mathrm{~b}$ shows a proof-of-concept demonstration, the integrated unit can function as a reliable power source to drive a portable electronic watch. The multivalent ion storage mechanism of the developed $\mathrm{ZHC}$ is presented in Fig. 1c. Highly reversible and fast ion $\left(\mathrm{Zn}^{2+}\right.$ and $\left.\mathrm{CF}_{3} \mathrm{SO}_{3}{ }^{-}\right)$adsorption/desorption storage mechanism occurs on the kelp-carbon cathode, $\mathrm{Zn}^{2+}$ depositing/stripping reaction occurs on the $\mathrm{Zn}$ anode, and $\mathrm{Zn}\left(\mathrm{CF}_{3} \mathrm{SO}_{3}\right)_{2}$ aqueous solution acts as the electrolyte.

\subsection{Characteristics of the Kelp-Carbon}

Kelp as a kind of brown algae is an extensive seafood worldwide. The biological structure of kelp blade is composed of meristoderm, outer cortex, inner cortex and medulla (Fig. 2a). To carry out effective photosynthesis in the sea, the surface layer (meristoderm) of kelp blade contains lots of chromatophores, which are made up of stacked nanolayered membranes and provide a high surface area. The cellulose and hemicellulose in the cell walls of the meristoderm, outer cortex, inner cortex, and medulla are pyrolyzed during carbonization, and form hierarchical, porous, and interconnected micro-/nano- architecture after activation (Fig. 2a, b).

The kelp-carbon presents ridge-like surface morphology consisting of stacked carbon nanosheets (Fig. 2c), corresponding to the meristoderm cellularity in the surface layer of kelp blade. The interior of the kelp-carbon owns a 3D cellular-like architecture (Fig. 2b, d), which consists 


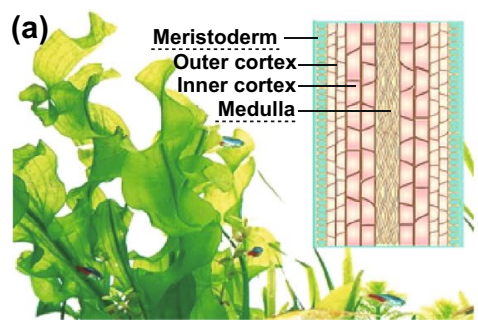

Kelp blade

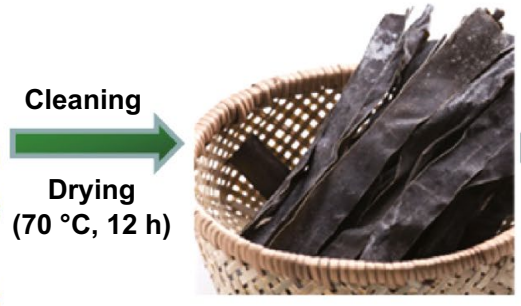

Dry kelp blade

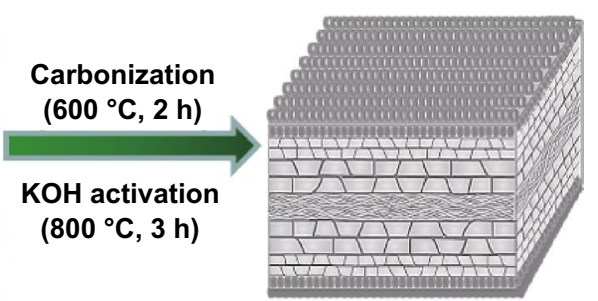

Kelp-carbon

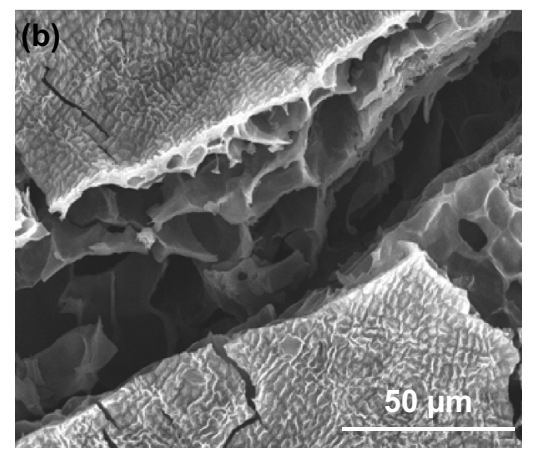

(e)

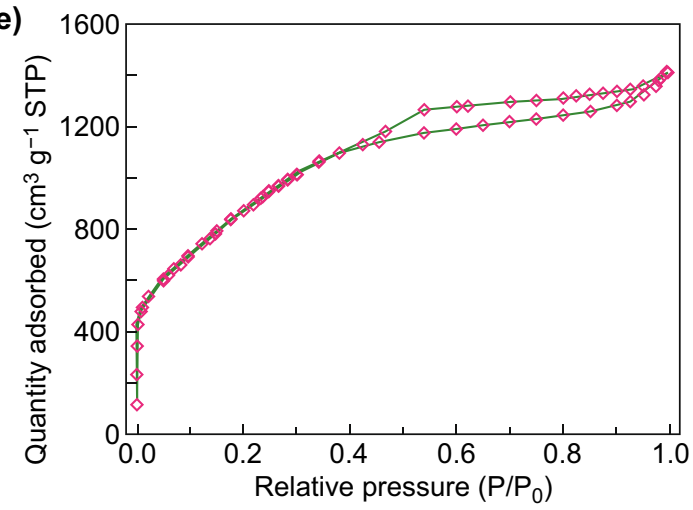

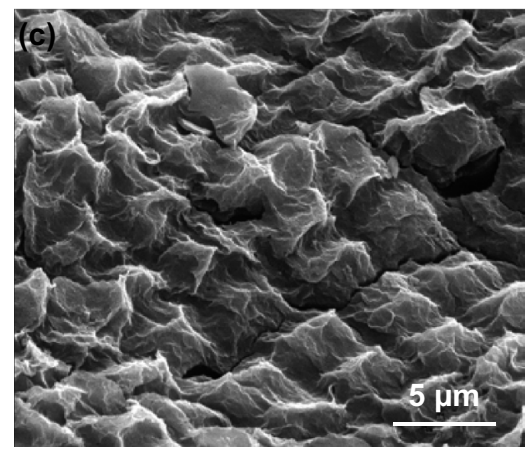
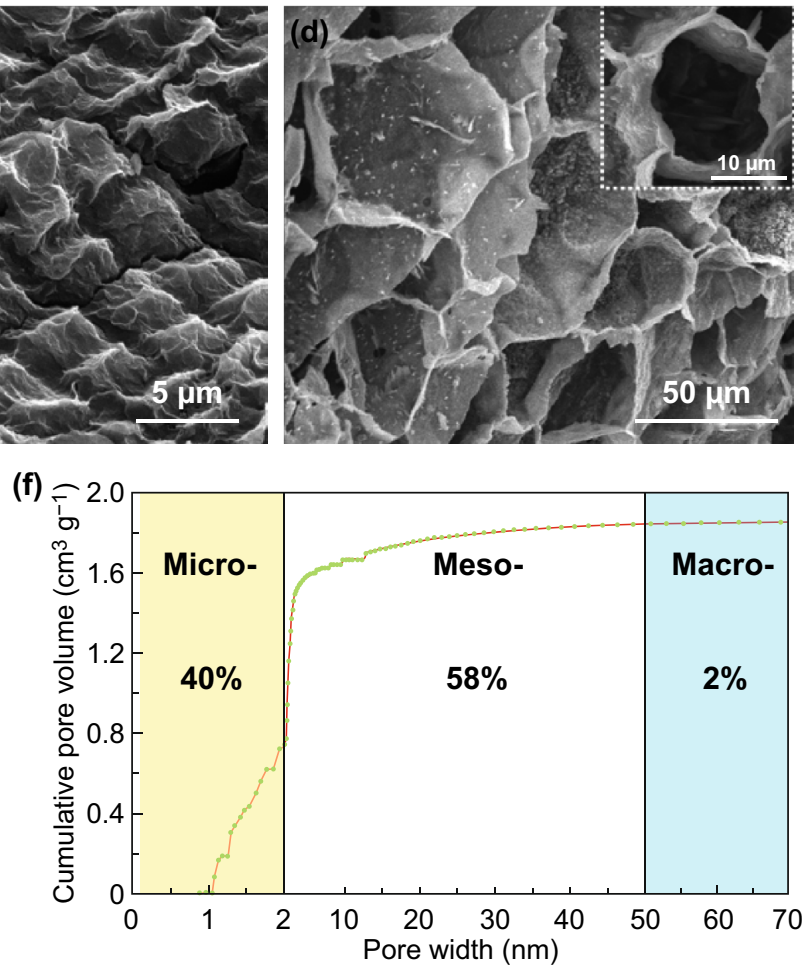

Fig. 2 a Main preparation process of kelp-carbon, including graphical illustrations on the microstructure of kelp blade and 3D hierarchical architecture of kelp-carbon. SEM images of the kelp-carbon: b overall morphology, $\mathbf{c}$ surface morphology, and $\mathbf{d}$ interior morphology. e $\mathrm{N}_{2}$ adsorption/desorption isotherm and $\mathbf{f}$ 2D-NLDFT pore size distribution of the kelp-carbon

of quadrilateral/pentagon-like cells and cell walls (carbon nanosheets). The sizes of the polygonal cells rang from ten to dozens of microns. Transmission electron microscope (TEM), Raman spectroscopy, and X-ray diffraction (XRD) investigations indicate the disordered (amorphous) carbon microstructure of the kelp-carbon (Fig. S1). X-ray photoelectron spectroscopy (XPS) confirms the presence of C, $\mathrm{O}, \mathrm{N}, \mathrm{S}$, and $\mathrm{P}$ elements in the kelp-carbon (Fig. S2a). The atomic fractions of $\mathrm{C}, \mathrm{O}, \mathrm{N}, \mathrm{S}$, and $\mathrm{P}$ are $88.81 \%, 9.89 \%$, $0.8 \%, 0.46 \%$, and $0.05 \%$, respectively. The contents of $\mathrm{N}$, $\mathrm{S}$, and $\mathrm{P}$ elements are relatively low. The high-resolution $\mathrm{C}$ $1 \mathrm{~s}$ spectrum (Fig. S2b) exhibits strong $s p^{2}$ carbon bonding $(284.35 \mathrm{eV})$ and relatively weak $\mathrm{C}-\mathrm{O}$ bonding $(286.4 \mathrm{eV})$.
The O $1 \mathrm{~s}$ spectrum (Fig. S2c) indicates the existence of a certain amount of oxygen-containing functional groups, including $\mathrm{H}_{2} \mathrm{O}-\mathrm{OH}$ bonding $\left(531.4 \mathrm{eV}\right.$ ), adsorbed $\mathrm{H}_{2} \mathrm{O}$ molecules $(532.5 \mathrm{eV})$ and $\mathrm{C}-\mathrm{O}$ groups $(533.8 \mathrm{eV})$. Brunauer-Emmett-Teller (BET)-specific surface area of the kelp-carbon reaches a high value of $3047 \mathrm{~m}^{2} \mathrm{~g}^{-1}$ according to $\mathrm{N}_{2}$ adsorption/desorption measurement (Fig. 2e). A hysteresis loop in the relative pressure range between 0.4 and 0.99 suggests the existence of mesopores and macropores. The pore size distribution curve (Fig. 2f) shows that the content of macropores is very low, micropores $\left(0.74 \mathrm{~cm}^{3} \mathrm{~g}^{-1}\right)$ and mesopores $\left(1.1 \mathrm{~cm}^{3} \mathrm{~g}^{-1}\right)$ occupying the most proportion. The total pore volume is as high as $1.87 \mathrm{~cm}^{3} \mathrm{~g}^{-1}$. The 

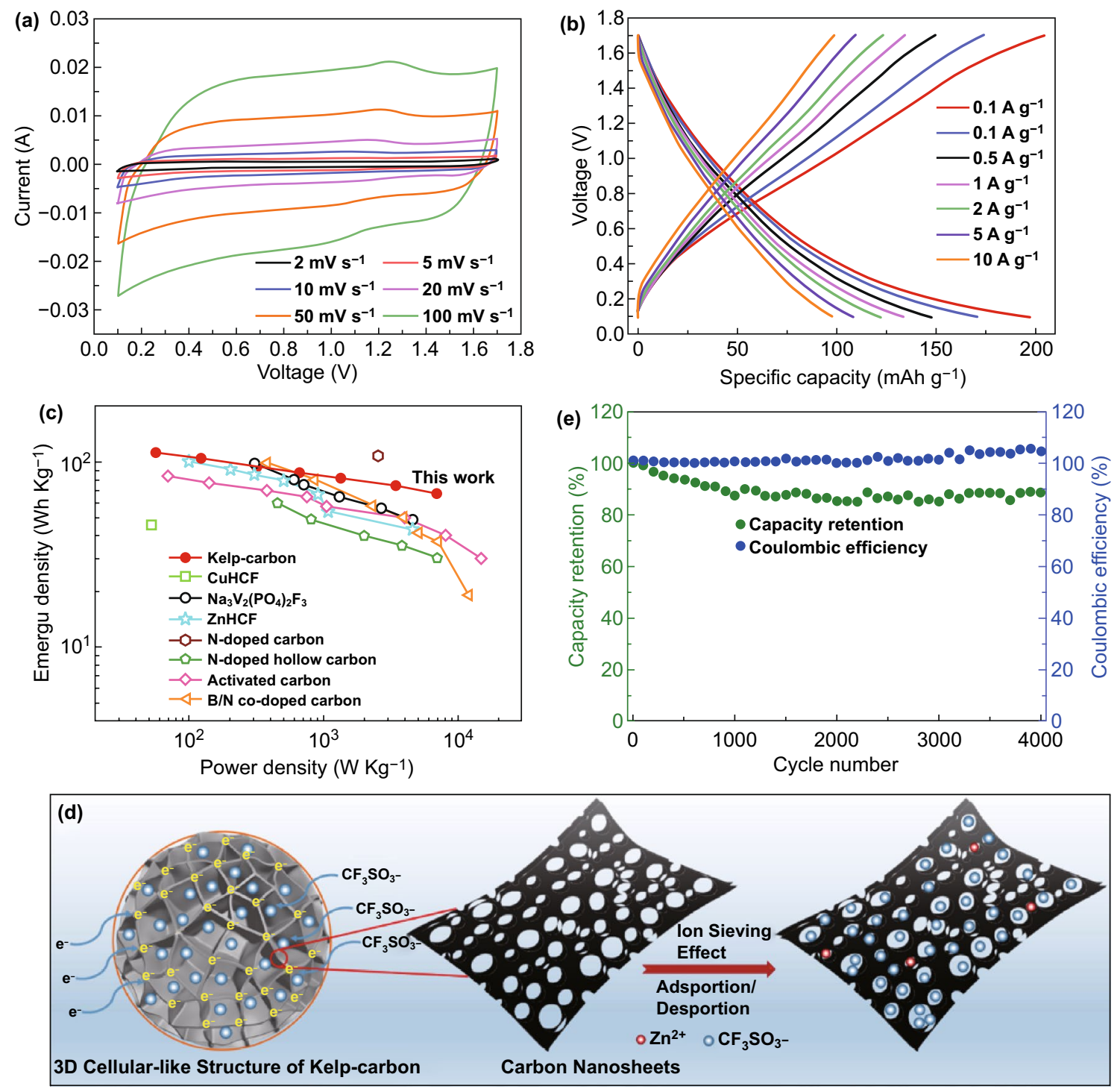

Fig. 3 a CV curves at different scan rates, b GCD curves at different current densities, and c Ragone plots of the aqueous ZHC. Energy densities of other aqueous ZHCs and Zn-ion batteries reported in literatures are provided for comparison. $\mathbf{d}$ Schematic of the 3D porous structure of kelp-carbon and the ion sieving effect for carbon nanosheets in electrochemical process. e Cycling performance of the device at $2 \mathrm{~A} \mathrm{~g}^{-1}$

polygonal cell walls and quadrilateral/pentagon-like channels in the kelp-carbon could provide sufficient pathways for the fast electron and ion diffusion.

\subsection{Electrochemical Properties of the Aqueous ZHCs}

Figure 3a shows the cyclic voltammetry (CV) curves at various scan rates of the assembled aqueous $\mathrm{ZHC}$ (kelp-carbon// $\mathrm{Zn}\left(\mathrm{CF}_{3} \mathrm{SO}_{3}\right)_{2} / / \mathrm{Zn}$ ) in a cell voltage range of $0.1-1.7 \mathrm{~V}$ (in a wider voltage range, water decomposition may occur, Fig.
S3) [22]. A pair of redox peaks located at 1.25 and $1.0 \mathrm{~V}$ are observed in the $\mathrm{CV}$ curves corresponding to the reactions of $\mathrm{Zn} / \mathrm{Zn}^{2+}$ depositing/stripping on $\mathrm{Zn}$ anode [19]. The shapes of the $\mathrm{CV}$ curves and positions of the redox peaks do not distort obviously with increasing scan rates, manifesting good rate capability of the hybrid capacitor [23].

Galvanostatic charge-discharge (GCD) measurement was devoted to evaluate the specific capacity, energy density, and power density of the ZHC. The GCD curves (Fig. 3b) present basically symmetrical, and the maximum specific capacity (based on the mass of kelp-carbon) is calculated 
to be $196.7 \mathrm{mAh} \mathrm{g}^{-1}$ (445 $\mathrm{F} \mathrm{g}^{-1}$ in specific capacitance) at $0.1 \mathrm{~A} \mathrm{~g}^{-1}$, and still holds $97.2 \mathrm{mAh} \mathrm{g}^{-1}\left(219 \mathrm{~F} \mathrm{~g}^{-1}\right)$ at $10 \mathrm{~A} \mathrm{~g}^{-1}$. The maximum energy density of the ZHC is up to $111.5 \mathrm{Wh} \mathrm{kg}^{-1}$ at $1300 \mathrm{~W} \mathrm{~kg}^{-1}$. High power densities of $1.3-6.9 \mathrm{~kW} \mathrm{~kg}^{-1}$ within $35-219 \mathrm{~s}$ can be obtained for the cell, which are much higher than those of common zincion batteries $[24,25]$. It is worth mentioning that the specific capacity and energy density of our aqueous ZHCs are superior to those of the reported aqueous ZHCs based on carbon cathodes, such as commercial activated carbon [18], $\mathrm{N}$-doped carbon [26], N-doped hollow carbon [27], and $\mathrm{B} / \mathrm{N}$-codoped carbon [28], and even precede those of some aqueous $\mathrm{Zn}$-ion batteries [29-31]. Electrochemical impedance spectroscopy (Fig. S4a) reveals reasonable equivalent series resistance $\left(R_{s}=13 \Omega\right)$ and charge transfer resistance $\left(R_{c t}=23.4 \Omega\right)$ for the ZHC [26, 32], implying good conductivity of the electrode materials and fast transport of electrolyte ions in the electrode and at the interfaces between the electrode and electrolyte.

The specific capacity of ZHC is mainly determined by the cathode material (kelp-carbon). Activated carbons with partial micropores are recommended for enhancing ion-trapping [33], while a certain proportion of mesopores/macropores is prerequisite to reduce the ion diffusion resistance (especially for ions with relatively large ion radius) and could serve as reservoirs for electrolyte ions [21]. Pore structure is like a filter for electrolyte ions (i.e., ion sieving effect) and the dimensions of pores and ions should match each other [33, 34]. As depicted in Fig. 2f, although the micropore sizes of the kelp-carbon $(0.9-2 \mathrm{~nm})$ are already larger than the hydrated ionic radii of $\mathrm{CF}_{3} \mathrm{SO}_{3}^{-}(>0.58 \mathrm{~nm})$ [35] and $\mathrm{Zn}^{2+}(0.43 \mathrm{~nm})$ [36]. In the actual ion adsorption/desorption process, a large number of bottleneck-type micropores generally exist in the activated carbons, which may block the rapid transport of electrolyte ions at high current densities and lead to poor rate capability [37]. Such phenomenon is announced from the control experiment by using commercial activated carbon (TF-B520) as cathode for the ZHCs. TF-B520 mainly contains micropores with an average pore size of $0.82 \mathrm{~nm}$ (Fig. S5). Due to the bottleneck effect of micropores and part of the micropores being underused, the ZHC based on TF-B520 cathode shows relatively low discharge-specific capacity $\left(129 \mathrm{mAh} \mathrm{g}^{-1}\right)$, worse rate performance, and higher $R_{\mathrm{ct}}(35 \Omega)$ (Fig. S6).

The Warburg region of the Nyquist plots (Fig. S7a) was further analyzed by replotting $Z^{\prime}$ (the real part of the collected impedance) as a function of $\omega^{-1 / 2}$ ( $\omega$ is the angular frequency) to reveal the ion diffusion resistivity in the kelp-carbon electrode. The slope of the linear fitting line is equal to diffusion resistivity, which reflects the ion diffusion impedance in the nanoporous carbons [38]. As shown in Fig. S7b, we can see that the slope of kelp-carbon is smaller than that of TF-B520, meaning reduced diffusion resistivity of ions in kelp-carbon electrode. Hence, we can conclude that the smaller $R_{\mathrm{ct}}$ and diffusion resistivity of kelp-carbon render its better rate capability performance (Figs. S4b and S6c). In our kelp-carbon, mesopores occupying the highest percentage (58\%) contribute to the fast diffusion/transport of relatively large electrolyte ions $\left(\mathrm{CF}_{3} \mathrm{SO}_{3}{ }^{-}\right.$and $\left.\mathrm{Zn}^{2+}\right)$. Except for the hierarchical pore structure, owing to the interior 3D cellular-like geometry of the kelp-carbon, the interconnected cell walls and interpenetrating quadrilateral/pentagon-like channels are able to offer sufficient pathways for achieving rapid electron transfer and ion diffusion at the same time (Fig. 3d). The above characteristics are important for achieving high specific capacity and good power density. In addition, the working voltage window of our aqueous $\mathrm{ZHC}$ $(1.6 \mathrm{~V})$ is wider than that of common aqueous $\mathrm{Zn}$-ion batteries (about 1 V) [39, 40]. High specific capacity combining with wide working voltage window contributes to the high energy densities of our ZHCs.

Considering supercapacitors generally present better capacitance retention at high current densities due to the limitation of diffusion rate and limited reactions. Cycling stability of the aqueous $\mathrm{ZHC}$ was investigated at a moderate current density of $2 \mathrm{~A} \mathrm{~g}^{-1}$ (Fig. 3e), which may announce more realistic cyclic stability of the cell. The specific capacity of the ZHC retains $89 \%$ of its initial value, and the coulombic efficiency holds $105 \%$ after 4,000 charge/discharge cycling test. The coulombic efficiency above $100 \%$ is due to the hydrogen evolution reaction (electrolysis of water) on $\mathrm{Zn}$ anode during discharging. Hydrogen evolution consumes electrons and promotes the zinc anode oxidation and generates more electrons to reach the cutoff voltage of $0.1 \mathrm{~V}$. Such reaction may contributes extra discharge capacity [41]. The reduction of capacity retention indicates some negative side-reactions occurred in the cycling process. In the mild acid electrolyte [ $2 \mathrm{M} \mathrm{Zn}\left(\mathrm{CF}_{3} \mathrm{SO}_{3}\right)_{2}$ aqueous solution with a $\mathrm{pH}$ value of $\sim 5.5]$, side-reactions for the aqueous ZHCs are mainly related to the inevitable hydrogen evolution reaction on $\mathrm{Zn}$ anode and the generation of poorly conductive by-products on electrodes. After 4,000 cycles, 

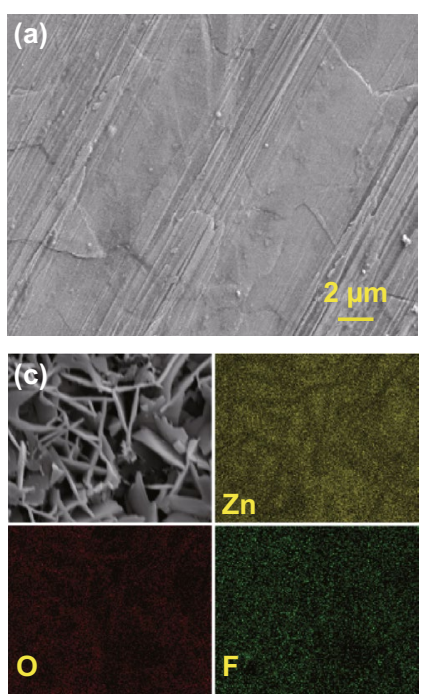
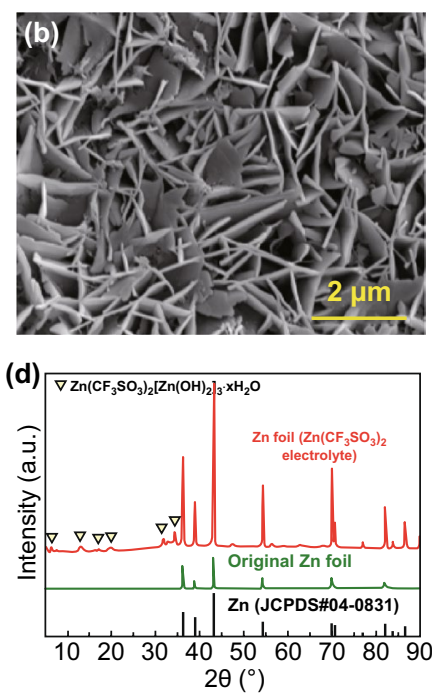
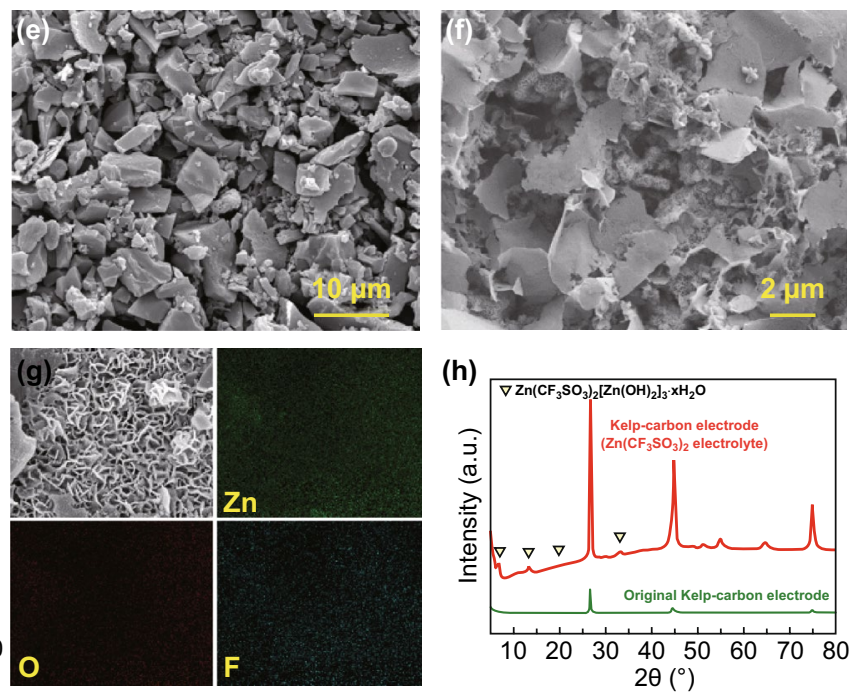

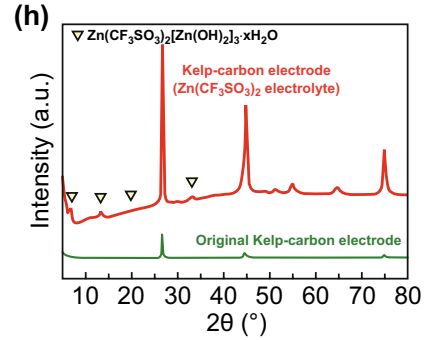

Fig. 4 SEM images on the surface of Zn foil anode: a original and $\mathbf{b}$ after 4,000 cycles. $\mathbf{c}$ Corresponding EDS mapping on the surface of Zn foil anode after 4,000 cycles. $\mathbf{d}$ XRD patterns of the anode before and after 4,000 cycles. SEM images on the surfaces of kelp-carbon cathode: $\mathbf{e}$ original and $\mathbf{f}$ after 4,000 cycles. $g$ Corresponding EDS mapping on the surface of kelp-carbon cathode after 4,000 cycles. $\mathbf{h}$ XRD patterns of the cathode before and after 4,000 cycles

plate-like $\mathrm{Zn}$ on $\mathrm{Zn}$ foil anode (Fig. 4a, b) and some thin nanosheets on the surface of kelp-carbon cathode (Fig. 4e, f) are observed. However, no obvious $\mathrm{Zn}$-dendrites generates on $\mathrm{Zn}$ anode in the mild acid electrolyte, because $\mathrm{Zn}$-dendrites problem generally happens in alkaline electrolyte [42]. Energy-dispersive spectrometer (EDS) mapping (Fig. 4c, d) and XRD analysis (Fig. 4g, h) reveal that by-product of $\mathrm{Zn}\left(\mathrm{CF}_{3} \mathrm{SO}_{3}\right)_{2}\left[\mathrm{Zn}(\mathrm{OH})_{2}\right]_{3} \cdot \mathrm{xH}_{2} \mathrm{O}$ generated on both electrodes $[43,44]$. During discharging, $\mathrm{Zn}^{2+}$ cations strip from the $\mathrm{Zn}$ anode and are adsorbed on the porous kelp-carbon cathode; during charging, $\mathrm{Zn}^{2+}$ cations deposit on the $\mathrm{Zn}$ anode and $\mathrm{CF}_{3} \mathrm{SO}_{3}{ }^{-}$anions are adsorbed on the kelp-carbon cathode. $\mathrm{Zn}^{2+}$ cations shuttle between the two electrodes. The precipitation/dissolution of $\mathrm{Zn}\left(\mathrm{CF}_{3} \mathrm{SO}_{3}\right)_{2}\left[\mathrm{Zn}(\mathrm{OH})_{2}\right]_{3} \cdot \mathrm{xH}_{2} \mathrm{O}$ participates forms according to reaction Eq. (1): phenomenon in aqueous $\mathrm{Zn}$-ion hybrid capacitors and $\mathrm{Zn}$ ion batteries $[18,43]$. The acceptable cycling stability of the aqueous $\mathrm{ZHC}$ at moderate current density benefits from the unique 3D hierarchical porous structure of the kelp-carbon and ample unimpeded pathways (interconnected cell walls and interpenetrating quadrilateral/pentagon-like channels) available for rapid electron and ion transport (Fig. 3d). Control experiment (Fig. S8) confirms that the microstructure of kelp-carbon is beneficial to alleviate the influence of byproduct precipitations on cycling stability of the aqueous ZHC. When using TF-B520 as the cathode, the capacity retention of the aqueous $\mathrm{ZHC}$ reduces to only $49 \%$ after 4,000 cycles. Different from the 3D cellular-like geometry and hierarchical pore structure of kelp-carbon, commercial activated carbon TF-B520 has a solid and micropore struc-

$4 \mathrm{Zn}^{2+}+6 \mathrm{OH}^{-}+2\left(\mathrm{CF}_{3} \mathrm{SO}_{3}\right)^{-}+\mathrm{xH}_{2} \mathrm{O} \Leftrightarrow \mathrm{Zn}\left(\mathrm{CF}_{3} \mathrm{SO}_{3}\right)_{2}\left[\mathrm{Zn}(\mathrm{OH})_{2}\right]_{3} \cdot \mathrm{xH}_{2} \mathrm{O} \downarrow$

Existence of $\mathrm{Zn}\left(\mathrm{CF}_{3} \mathrm{SO}_{3}\right)_{2}\left[\mathrm{Zn}(\mathrm{OH})_{2}\right]_{3} \cdot \mathrm{xH}_{2} \mathrm{O}$ on both electrodes indicates enhanced $\mathrm{pH}$ value of the $\mathrm{Zn}\left(\mathrm{CF}_{3} \mathrm{SO}_{3}\right)_{2}$ electrolyte and generation of $\mathrm{OH}^{-}$induced by hydrogen evolution reaction in our aqueous $\mathrm{ZHCs}$, yet it is a common ture. The micropores on the surface of TF-B520 can be easily blocked by by-product precipitations, and lack of open interpenetrating channels in TF-B520 results in poor cycling stability of the cell. 
(a)
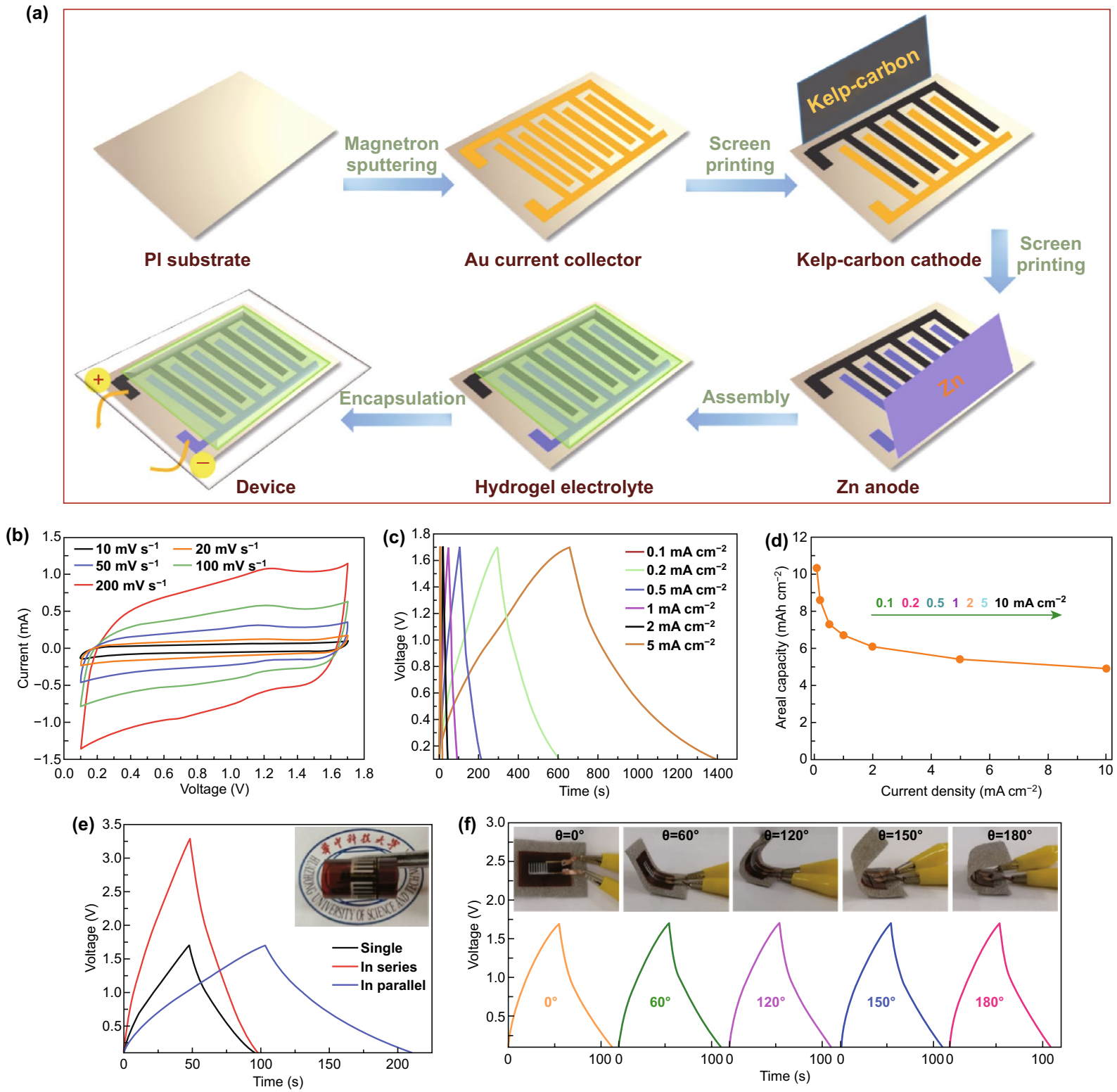

Fig. 5 a Fabrication procedure for the flexible quasi-solid-state micro-ZHCs. b CV curves of the micro-ZHCs at different scan rates. $\mathbf{c}$ GCD curves at different current densities. d Areal capacity and rate capability. e GCD curves at $1 \mathrm{~mA} \mathrm{~cm}{ }^{-2}$ of a single cell, and two cells connected in series or parallel. The inset shows two cells connected in series and good flexibility of the device. $\mathbf{f}$ GCD curves at $1 \mathrm{~mA} \mathrm{~cm}-2$ of the microZHCs under different bending angles from $0^{\circ}$ to $180^{\circ}$

\subsection{Construction of Flexible Micro-ZHCs via Screen Printing}

In quest to miniaturized, lightweight, and wearable energy storage devices, we developed flexible quasi-solid-state micro-ZHCs via a facile and economic screen-printing technique. Figure 5a describes the simple preparation process. The Au current collectors were deposited by magnetron sputtering, followed by screen printing kelp-carbon cathode and $\mathrm{Zn}$ powder anode, and coating the printed interdigital electrodes with $\mathrm{Zn}\left(\mathrm{CF}_{3} \mathrm{SO}_{3}\right)_{2}$-PAM hydrogel electrolyte finally. The crosslinked PAM polymer chains can form an ion conductive network with superb water absorption ability and flexibility, as exhibited in Fig. S9. The ionic conductivity of the $\mathrm{Zn}\left(\mathrm{CF}_{3} \mathrm{SO}_{3}\right)_{2}$-PAM hydrogel electrolyte is up to $12.2 \mathrm{mS} \mathrm{cm}^{-1}$, as determined by the electrochemical 
impedance test (Fig. S10). The surface morphology of the obtained interdigital electrodes after screen printing (printing one layer) is shown in Fig. S11a. The width of one electrode finger and interspace between the cathode and anode fingers are 400 and $250 \mu \mathrm{m}$, respectively (Fig. S11b, c). The thicknesses of the kelp-carbon cathode and the $\mathrm{Zn}$ powder anode determined by SEM are about 10 and $10.35 \mu \mathrm{m}$, respectively (Fig. S12).

To evaluate the electrochemical performances of the printed quasi-solid-state micro-ZHCs, CV and GCD measurements with a voltage range from 0.1 to $1.7 \mathrm{~V}$ were carried out. The CV curves (Fig. 5b) with a pair of redox peaks are in line with the results of Fig. 3a, attributed to the hybrid energy storage mechanism. Even at high scan rates, the quasi-rectangle shapes are well maintained, indicating excellent rate capability of the micro-ZHCs. Compared with the aforementioned stacked ZHCs, in-plane micro-ZHCs possess better rate capability due to the architecture of interdigital microelectrodes, which could reduce the ion transport path and make full use of the active materials. The GCD curves demonstrate symmetrical triangular shapes with no apparent internal resistance drop. The highest areal capacity of the device (based on the total area of positive and negative electrodes) reaches $10.28 \mu \mathrm{Ah} \mathrm{cm}^{-2}$ at a current density of $0.1 \mathrm{~mA} \mathrm{~cm}^{-2}$ (Fig. $5 \mathrm{c}$, d). The micro-ZHC has an areal energy density of $8.2 \mu \mathrm{Wh} \mathrm{cm} \mathrm{cm}^{-2}$ at a power density of $40 \mu \mathrm{W} \mathrm{cm}{ }^{-2}$ and still maintain $3.9 \mu \mathrm{Wh} \mathrm{cm}^{-2}$ at $4 \mathrm{~mW} \mathrm{~cm}^{-2}$. It is worth mentioning that we just print one layer of electrode materials on the Au current collectors. However, the thickness and mass loading of the active electrode material can be further increased by multiple printing $[45,46]$. This is an advantage by using screen printing technology. Even so, the areal energy density of our micro-ZHC is comparable to those of the recently reported in-plane micro-supercapacitors based on carbon materials [47-51]. More information on the specific capacity/capacitance and energy/power density of the micro-ZHC based on different metrics (areal or volumetric performance) is summarized in Table $\mathrm{S} 1$ for cross-lab comparison.

Moreover, the voltage window or output current of the device can be enlarged by printing the electrode arrays in series or parallel to meet the energy/power requirement. Figures 5e and S13a show that the operating voltage and output current are readily doubled when two micro-ZHCs are connected in series and in parallel, respectively. In series connection, the voltage window reaches up to $3.2 \mathrm{~V}$ which is twice the value of a single $\mathrm{ZHC}$, and there is a degradation in the output current due to the increased resistance. In parallel connection, the ZHCs provide nearly twice the output current of a single ZHC, while holding the same voltage window as that of the single cell. Owing to the flexibility of the microelectrodes and hydrogel electrolyte, the fabricated micro-ZHCs could subject to mechanical bending with maintained capacitive functionality. To evaluate the mechanical robustness of the printed micro-ZHC, the device was subjected to mechanical bending from $0^{\circ}$ to $180^{\circ}$ (Figs. 5f and S13b) and repeated bending at $120^{\circ}$ for 100 cycles (Fig. S14), the CV and GCD curves resemble the ones under flat state with capacity retention close to $100 \%$. The negligible effect of bending on the electrochemical properties of the micro-ZHC indicates good adhesion between $\mathrm{Au}$ current collector and electrodes. Such printed micro-ZHCs with impressive mechanical and electrochemical stabilities promise multi-field integration applications.

\subsection{Integration of Flexible Solar-Charging Self-Powered Units}

To build a solar-charging self-powered unit, micro-ZHC serving as the energy storage module and four-junction OSCs working as the energy conversion component are integrated on PET substrate. The performance and the photovoltaic parameters of the single flexible OSC under different light sources (AM 1.5G and LED) are provided in Fig. S15 and Table S2. The energy conversion efficiency of the OSC reaches $21.2 \%$ at the indoor light intensity $\left(0.135 \mathrm{~mW} \mathrm{~cm}^{-2}\right)$. Considering that the standard sunlight intensity is not always available (such as cloudy and rainy days), and we usually work and live in the indoor environment, it is very necessary to evaluate the performance of the self-powered integrated unit at weak light intensities. The solar-charging/discharging performance of the integrated system was evaluated under varied indoor light intensities $\left(0.135-4.14 \mathrm{~mW} \mathrm{~cm}^{-2}\right)$ with homologous discharge current density (Fig. 6a). The system worked well in a wide range of light intensities with no obvious IR drop observed in the solar-charging/discharging curves (thus low energy loss), and the charging time can be adjusted according to the light intensity. The output current density of the OSCs corresponding to light intensity is shown in Fig. 6b. The highest energy conversion/storage efficiency $\left(\eta_{\text {overall }}\right)$ of the integrated unit reached $17.8 \%$ at a 

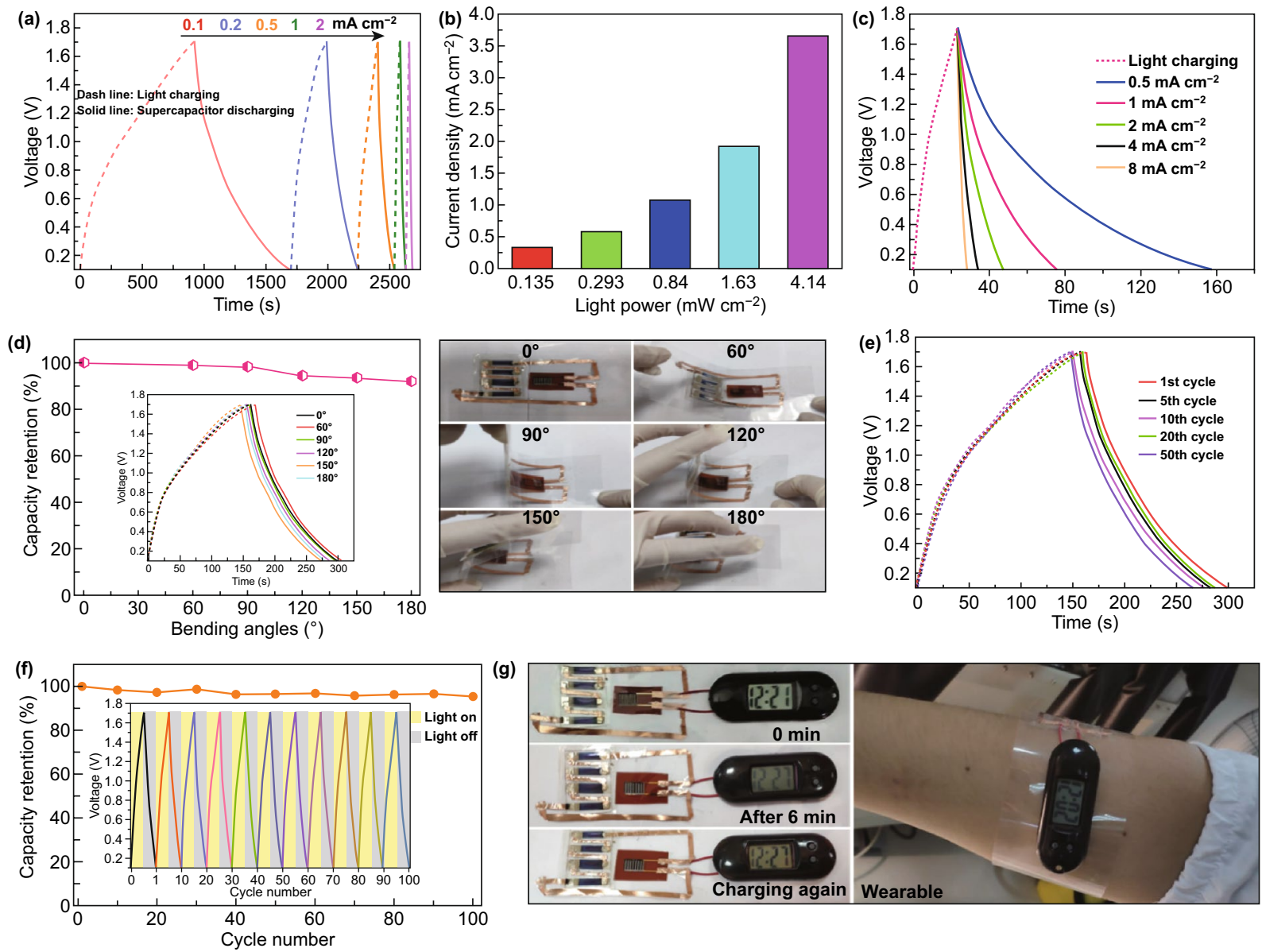

Fig. 6 a Solar-charging/discharging curves of the integrated self-powered unit at different light intensities/discharge current densities. b Output current densities of the OSCs at different light intensities. c Solar-charging/discharging curves at the same light intensity and different discharge current densities. d Capacity retentions of the unit at different bending angles from $0^{\circ}$ to $180^{\circ}$ and corresponding GCD curves. e Cycling stability of the unit at a bending angle of $120^{\circ}$ for 50 cycles. $\mathbf{f}$ Cycling performance of the unit at $1 \mathrm{~mA} \mathrm{~cm}{ }^{-2}$. $\mathbf{g}$ Proof-of-concept demonstration of the flexible solar-charging self-powered unit powering an electronic watch

light intensity of $0.135 \mathrm{~mW} \mathrm{~cm}{ }^{-2}$. As shown in Fig. 6c, the integrated unit can be charged to $1.6 \mathrm{~V}$ in $23 \mathrm{~s}$, demonstrating fast photoelectric conversion rate. Moreover, the integrated unit was discharged at different current densities from 0.5 to $8 \mathrm{~mA} \mathrm{~cm}^{-2}$, and the diploid discharge time implies a favorable rate performance.

We further investigated the mechanical stability of the integrated system. Figure 6d shows the solar-charging $\left(0.84 \mathrm{~mW} \mathrm{~cm}^{-2}\right) /$ discharging $\left(0.5 \mathrm{~mA} \mathrm{~cm}^{-2}\right)$ profiles at various bending angles $\left(60^{\circ}, 90^{\circ}, 120^{\circ}, 150^{\circ}\right.$, and $\left.180^{\circ}\right)$. The roughly superposed charge/discharge curves demonstrate excellent flexibility and electrochemical stability of our self-powered unit. The mechanical durability was further explored by repeatedly bending the device at $120^{\circ}$ for 50 cycles (Fig. 6e). The capacity retained $86 \%$ of its original value after 50 bending cycles, indicating decent mechanical stability of the self-powered unit. The cycling stability of the system was firstly investigated at a solar-charging intensity of $1.63 \mathrm{~mW} \mathrm{~cm}^{-2}$ and discharge current density of $1 \mathrm{~mA} \mathrm{~cm}^{-2}$ (Fig. 6f). Impressively, the system exhibits superb cycling stability with a capacity retention of $95 \%$ after 100 cycles. Then, we conducted the cycling test on the system at a higher solar-charging intensity of $4.14 \mathrm{~mW} \mathrm{~cm}^{-2}$ (which is the highest light intensity that our indoor light source, i.e., LED lamp can provide) and discharge current density of $2 \mathrm{~mA} \mathrm{~cm}^{-2}$ (Fig. S16). The system presents a capacity retention of $91 \%$ after 100 cycles, slightly lower than the value at a solar-charging intensity of $1.63 \mathrm{~mW} \mathrm{~cm}^{-1}$ 
(95\%) due to the higher charge-discharge current densities for the micro-ZHC. Considering the good flexibility and electrochemical stability of the self-powered unit, it is befitting to be applied in wearable scenarios. We utilized the flexible self-powered unit as a "wearable wristband" to power an electronic watch $(1.5 \mathrm{~V})$. The electronic watch could work for a long time when the wristband was exposed to indoor natural sunlight after fast charging at a light intensity of $12 \mathrm{~mW} \mathrm{~cm}^{-2}$ (Fig. $6 \mathrm{~g}$ ). Moreover, energy stored in the micro-ZHC could power the electronic watch for more than 6 min in dark, after that the system could return to normal work just by solar-charging again, demonstrating a green energy system.

\section{Conclusions}

A low cost, safe, durable, and flexible solar-charging integrated unit is developed. The system consists of OSCs and a micro-ZHC acting as energy conversion and storage module, respectively. The in-plane asymmetric printing technology employed by micro-ZHCs is an economic, facile, and versatile fabrication method. The unique 3D hierarchical architecture of kelp-carbon and multivalent ion storage mechanism endow the micro-ZHCs with high areal capacity of $10.28 \mu \mathrm{Ah} \mathrm{cm}^{-2}$ and high energy density of $8.2 \mu \mathrm{Wh} \mathrm{cm}^{-2}$. The integrated unit exhibits fast photoelectric conversion characteristic (charged to $1.6 \mathrm{~V}$ in $23 \mathrm{~s}$ ) with tolerance for a wide variation of light intensity (0.135-4.14 $\left.\mathrm{mW} \mathrm{cm}^{-2}\right)$. It shows excellent mechanical robustness and cycling stability (with a capacity retention of $95 \%$ after 100 cycles). Moreover, the integrated unit can power an electronic watch easily under indoor natural light, demonstrating its wearability and practicality. Such portable, wearable, and green self-powered unit is believed to be a new guide for design of energy integrated systems toward the goal of developing highly safe, light weight, economic, and long-life smart wearable electronics.

Acknowledgements This work was supported by the National Natural Science Foundation of Hubei Province (Grant No. 2019CFB110) and the fund of the Shaanxi Key Laboratory of Fiber Reinforced Light Composite Materials (Grant No. 1-KF-2019). The Analytical and Testing Center of Huazhong University of Science and Technology is acknowledged for the SEM, TEM, Raman, and XRD investigations.
Open Access This article is licensed under a Creative Commons Attribution 4.0 International License, which permits use, sharing, adaptation, distribution and reproduction in any medium or format, as long as you give appropriate credit to the original author(s) and the source, provide a link to the Creative Commons licence, and indicate if changes were made. The images or other third party material in this article are included in the article's Creative Commons licence, unless indicated otherwise in a credit line to the material. If material is not included in the article's Creative Commons licence and your intended use is not permitted by statutory regulation or exceeds the permitted use, you will need to obtain permission directly from the copyright holder. To view a copy of this licence, visit http://creativecommons.org/licenses/by/4.0/.

Electronic supplementary material The online version of this article (https://doi.org/10.1007/s40820-020-00546-7) contains supplementary material, which is available to authorized users.

\section{References}

1. S. Park, S.W. Heo, W. Lee, D. Inoue, Z. Jiang et al., Selfpowered ultra-flexible electronics via nanograting-patterned organic photovoltaics. Nature 561, 516-521 (2018). https:// doi.org/10.1038/s41586-018-0536-x

2. Y. Yang, W. Gao, Wearable and flexible electronics for continuous molecular monitoring. Chem. Soc. Rev. 48, 1465-1491 (2019). https://doi.org/10.1039/C7CS00730B

3. H. Lee, T.K. Choi, Y.B. Lee, H.R. Cho, R. Ghaffari et al., A graphene-based electrochemical device with thermoresponsive microneedles for diabetes monitoring and therapy. Nat. Nanotechnol. 11, 566-572 (2016). https://doi.org/10.1038/ nnano.2016.38

4. M.K. Choi, J. Yang, K. Kang, D.C. Kim, C. Choi et al., Wearable red-green-blue quantum dot light-emitting diode array using high-resolution intaglio transfer printing. Nat. Commun. 6, 7149 (2015). https://doi.org/10.1038/ncomms8149

5. Q. Shi, Z. Zhang, T. Chen, C. Lee, Minimalist and multi-functional human machine interface (HMI) using a flexible wearable triboelectric patch. Nano Energy 62, 355-366 (2019). https://doi.org/10.1016/j.nanoen.2019.05.033

6. M. Qiu, P. Sun, G. Cui, Y. Tong, W. Mai, A flexible microsupercapacitor with integral photocatalytic fuel cell for selfcharging. ACS Nano 13, 8246-8255 (2019). https://doi. org/10.1021/acsnano.9b03603

7. Z. Tian, X. Tong, G. Sheng, Y. Shao, L. Yu et al., Printable magnesium ion quasi-solid-state asymmetric supercapacitors for flexible solar-charging integrated units. Nat. Commun. 10, 4913 (2019). https://doi.org/10.1038/s41467-019-12900-4

8. J. Zhang, H.S. Tan, X. Guo, A. Facchetti, H. Yan, Material insights and challenges for non-fullerene organic solar cells based on small molecular acceptors. Nat. Energy 3, 720-731 (2018). https://doi.org/10.1038/s41560-018-0181-5 
9. Y. Wang, Y. Song, Y. Xia, Electrochemical capacitors: mechanism, materials, systems, characterization and applications. Chem. Soc. Rev. 45, 5925-5950 (2016). https://doi. org/10.1039/C5CS00580A

10. S. Zhai, H.E. Karahan, C. Wang, Z. Pei, L. Wei, Y. Chen, 1D Supercapacitors for emerging electronics: current status and future directions. Adv. Mater. 32, 1902387 (2020). https://doi. org/10.1002/adma.201902387

11. Y. Dong, S. Zhang, X. Du, S. Hong, S. Zhao et al., Boosting the electrical double-layer capacitance of graphene by selfdoped defects through ball-milling. Adv. Funct. Mater. 29, 1901127 (2019). https://doi.org/10.1002/adfm.201901127

12. B. Asbani, C. Douard, T. Brousse, J.L. Bideau, High temperature solid-state supercapacitor designed with ionogel electrolyte. Energy Storage Mater. 21, 439-445 (2019). https://doi. org/10.1016/j.ensm.2019.06.004

13. H. Wang, C. Zhu, D. Chao, Q. Yan, H.J. Fan, Nonaqueous hybrid lithium-ion and sodium-ion capacitors. Adv. Mater. 29, 1702093 (2017). https://doi.org/10.1002/adma.201702093

14. D.P. Dubal, O. Ayyad, V. Ruiz, P. Gomez-Romero, Hybrid energy storage: the merging of battery and supercapacitor chemistries. Chem. Soc. Rev. 44, 1777-1790 (2015). https:// doi.org/10.1039/C4CS00266K

15. X. Zhang, Z. Pei, C. Wang, Z. Yuan, L. Wei et al., Flexible zinc-ion hybrid fiber capacitors with ultrahigh energy density and long cycling life for wearable electronics. Small 15, 1903817 (2019). https://doi.org/10.1002/smll.201903817

16. J. Ding, W. Hu, E. Paek, D. Mitlin, Review of hybrid ion capacitors: from aqueous to lithium to sodium. Chem. Rev. 118, 6457-6498 (2018). https://doi.org/10.1021/acs.chemr ev.8b00116

17. L. Dong, W. Yang, W. Yang, Y. Li, W. Wu, G. Wang, Multivalent metal ion hybrid capacitors: a review with a focus on zinc-ion hybrid capacitors. J. Mater. Chem. A 7, 13810-13832 (2019). https://doi.org/10.1039/C9TA02678A

18. L. Dong, X. Ma, Y. Li, L. Zhao, W. Liu et al., Extremely safe, high-rate and ultralong-life zinc-ion hybrid supercapacitors. Energy Storage Mater. 13, 96-102 (2018). https://doi. org/10.1016/j.ensm.2018.01.003

19. H. Wang, M. Wang, Y. Tang, A novel zinc-ion hybrid supercapacitor for long-life and low-cost energy storage applications. Energy Storage Mater. 13, 1-7 (2018). https://doi. org/10.1016/j.ensm.2017.12.022

20. C. Wang, K. Xia, H. Wang, X. Liang, Z. Yin, Y. Zhang, Advanced carbon for flexible and wearable electronics. Adv. Mater. 31, 1801072 (2019). https://doi.org/10.1002/ adma.201801072

21. J. Zeng, L. Wei, X. Guo, Bio-inspired high-performance solidstate supercapacitors with the electrolyte, separator, binder and electrodes entirely from kelp. J. Mater. Chem. A 5, 2528225292 (2017). https://doi.org/10.1039/C7TA08095F

22. G. Sun, H. Yang, G. Zhang, J. Gao, X. Jin et al., A capacity recoverable zinc-ion micro-supercapacitor. Energy Environ. Sci. 11, 3367-3374 (2018). https://doi.org/10.1039/C8EE0 $2567 \mathrm{C}$
23. L. Dong, C. Xu, Y. Li, Z. Pan, G. Liang et al., Breathable and wearable energy storage based on highly flexible paper electrodes. Adv. Mater. 28, 9313-9319 (2016). https://doi. org/10.1002/adma.201602541

24. Y. Zhao, L. Ma, Y. Zhu, P. Qin, H. Li et al., Inhibiting grain pulverization and sulfur dissolution of bismuth sulfide by ionic liquid enhanced poly(3,4ethylenedioxythiophene):poly(styre nesulfonate) for high-performance zinc-ion batteries. ACS Nano 13, 7270-7280 (2019). https://doi.org/10.1021/acsna no. 9 b02986

25. C. Xie, H. Zhang, W. Xu, W. Wang, X. Li, A long cycle life, self-healing zinc-iodine flow battery with high power density. Angew. Chem. Int. Ed. 57, 11171-11176 (2018). https://doi. org/10.1002/anie.201803122

26. H. Zhang, Q. Liu, Y. Fang, C. Teng, X. Liu et al., Boosting Znion energy storage capability of hierarchically porous carbon by promoting chemical adsorption. Adv. Mater. 31, 1904948 (2019). https://doi.org/10.1002/adma.201904948

27. S. Chen, L. Ma, K. Zhang, M. Kamruzzaman, C. Zhi, J.A. Zapien, A flexible solid-state zinc ion hybrid supercapacitor based on co-polymer derived hollow carbon spheres. J. Mater. Chem. A 7, 7784-7790 (2019). https://doi.org/10.1039/C9TA0 0733D

28. Y. Lu, Z. Li, Z. Bai, H. Mi, C. Ji et al., High energy-power Znion hybrid supercapacitors enabled by layered $\mathrm{B} / \mathrm{N}$ co-doped carbon cathode. Nano Energy 66, 104132 (2019). https://doi. org/10.1016/j.nanoen.2019.104132

29. W. Li, K. Wang, S. Cheng, K. Jiang, A long-life aqueous Zn-ion battery based on $\mathrm{Na}_{3} \mathrm{~V}_{2}\left(\mathrm{PO}_{4}\right)_{2} \mathrm{~F}_{3}$ cathode. Energy Storage Mater. 15, 14-21 (2018). https://doi.org/10.1016/j. ensm.2018.03.003

30. L. Zhang, L. Chen, X. Zhou, Z. Liu, Towards high-voltage aqueous metal-ion batteries beyond $1.5 \mathrm{~V}$ : the zinc/zinc hexacyanoferrate system. Adv. Energy Mater. 5, 1400930 (2015). https://doi.org/10.1002/aenm.201400930

31. R. Trocoli, F.L. Mantia, An aqueous zinc-ion battery based on copper hexacyanoferrate. Chemsuschem 8, 481-485 (2015). https://doi.org/10.1002/cssc.201403143

32. P. Liu, W. Liu, Y. Huang, P. Li, J. Yan, K. Liu, Mesoporous hollow carbon spheres boosted, integrated high performance aqueous $\mathrm{Zn}$-ion energy storage. Energy Storage Mater. 25, 858-865 (2020). https://doi.org/10.1016/j.ensm.2019.09.004

33. F. Beguin, V. Presser, A. Balducci, E. Frackowiak, Carbons and electrolytes for advanced supercapacitors. Adv. Mater. 26, 2219-2251 (2014). https://doi.org/10.1002/adma.201304137

34. L. Chen, G. Shi, J. Shen, B. Peng, B. Zhang et al., Ion sieving in graphene oxide membranes via cationic control of interlayer spacing. Nature 550, 380-383 (2017). https://doi.org/10.1038/ nature 24044

35. Z. Li, S. Ganapathy, Y. Xu, Z. Zhou, M. Sarilar, M. Wagemaker, Mechanistic insight into the electrochemical performance of $\mathrm{Zn} / \mathrm{VO}_{2}$ batteries with an aqueous $\mathrm{ZnSO}_{4}$ electrolyte. Adv. Energy Mater. 9, 1900237 (2019). https://doi. org/10.1002/aenm.201900237

36. W. Qiu, Y. Zheng, Removal of lead, copper, nickel, cobalt, and zinc from water by a cancrinite-type zeolite synthesized 
from fly ash. Chem. Eng. J. 145, 483-488 (2009). https://doi. org/10.1016/j.cej.2008.05.001

37. M. Zeller, V. Lorrmann, G. Reichenauer, M. Wiener, J. Pflaum, Relationship between structural properties and electrochemical characteristics of monolithic carbon xerogel-based electrochemical double-layer electrodes in aqueous and organic electrolytes. Adv. Energy Mater. 2, 598-605 (2012). https:// doi.org/10.1002/aenm.201100513

38. Y. Song, T. Liu, M. Li, B. Yao, T. Kou et al., Engineering of mesoscale pores in balancing mass loading and rate capability of hematite films for electrochemical capacitors. Adv. Energy Mater. 8, 1801784 (2018). https://doi.org/10.1002/aenm.20180 1784

39. W. Xu, K. Zhao, W. Huo, Y. Wang, G. Yao et al., Diethyl ether as self-healing electrolyte additive enabled long-life rechargeable aqueous zinc ion batteries. Nano Energy 62, 275-281 (2019). https://doi.org/10.1016/j.nanoen.2019.05.042

40. F. Wan, L. Zhang, X. Dai, X. Wang, Z. Niu, J. Chen, Aqueous rechargeable zinc/sodium vanadate batteries with enhanced performance from simultaneous insertion of dual carriers. Nat. Commun. 9, 1656 (2018). https://doi.org/10.1038/s4146 7-018-04060-8

41. C. Han, W. Li, H.K. Liu, S. Dou, J. Wang, Principals and strategies for constructing a highly reversible zinc metal anode in aqueous batteries. Nano Energy 74, 104880 (2020). https:// doi.org/10.1016/j.nanoen.2020.104880

42. C. Li, X. Xie, S. Liang, J. Zhou, Issues and future perspective on zinc metal anode for rechargeable aqueous zinc-ion batteries. Energy Environ. Mater. 3, 146-159 (2020). https://doi. org/10.1002/eem2.12067

43. L. Dong, W. Yang, W. Yang, C. Wang, Y. Li et al., High-power and ultralong-life aqueous zinc-ion hybrid capacitors based on pseudocapacitive charge storage. Nano-Micro Lett. 11, 94 (2019). https://doi.org/10.1007/s40820-019-0328-3

44. Y. Jin, L. Zou, L. Liu, M.H. Engelhard, R.L. Patel et al., Joint charge storage for high-rate aqueous zinc-manganese dioxide batteries. Adv. Mater. 31, 1900567 (2019). https:// doi.org/10.1002/adma.201900567

45. X. Zhang, W. Zhao, L. Wei, Y. Jin, J. Hou, X. Wang, X. Guo, In-plane flexible solid-state microsupercapacitors for onchip electronics. Energy 170, 338-348 (2019). https://doi. org/10.1016/j.energy.2018.12.184

46. W. Zhao, L. Wei, Q. Fu, X. Guo, High-performance, flexible, solid-state micro-supercapacitors based on printed asymmetric interdigital electrodes and bio-hydrogel for on-chip electronics. J. Power Sources 422, 73-83 (2019). https://doi. org/10.1016/j.jpowsour.2019.03.021

47. J. Xu, Y. He, S. Bi, M. Wang, P. Yang et al., An olefin-linked covalent organic framework as a flexible thin-film electrode for a high-performance micro-supercapacitor. Angew. Chem. Int. Ed. 131, 12193-12197 (2019). https://doi.org/10.1002/ ange. 201905713

48. Y. Yue, N. Liu, Y. Ma, S. Wang, W. Liu et al., Highly selfhealable 3D microsupercapacitor with MXene-graphene composite aerogel. ACS Nano 12, 4224-4232 (2018). https://doi. org/10.1021/acsnano.7b07528

49. J. Cai, C. Lv, C. Hu, J. Luo, S. Liu et al., Laser direct writing of heteroatom-doped porous carbon for high-performance micro-supercapacitors. Energy Storage Mater. 25, 404-415 (2020). https://doi.org/10.1016/j.ensm.2019.10.001

50. W. Zhang, Y. Lei, F. Ming, Q. Jiang, P.M.F.J. Costa, H.N. Alshareef, Lignin laser lithography: a direct-write method for fabricating 3D graphene electrodes for microsupercapacitors. Adv. Energy Mater. 8, 1801840 (2018). https://doi. org/10.1002/aenm.201801840

51. J. Yoo, S. Byun, C.-W. Lee, C.-Y. Yoo, J. Yu, Precisely geometry controlled microsupercapacitors for ultrahigh areal capacitance, volumetric capacitance, and energy density. Chem. Mater. 30, 3979-3990 (2018). https://doi.org/10.1021/acs. chemmater.7b03786 